\title{
Research on the Actuality and Development of Graduate Education in Jilin Province
}

\author{
Yan Bao ${ }^{1, a}$ and Chunyan Wang ${ }^{2, b}$ \\ ${ }^{1}$ Scientific Research Office, Jilin Engineering Normal University, Changchun, China \\ ${ }^{2}$ College of Business Administration, Jilin Engineering Normal University, Changchun, China \\ a369275690@qq.com, ${ }^{\mathrm{b}} 541012329 @ q q . c o m$,
}

Keywords: Jilin Province; Graduate education; Actuality; Development

\begin{abstract}
The graduate education in Jilin Province started earlier and has been showing a relatively stable structure after many years of exploration and development. But there are still several problems, such as an imbalance between academic education and professional education, the imperfect quality of graduate education, the poor implementation of education program and so on. This paper introduces the general situation of graduate education in Jilin Province, analyzes the existing problems in the system of graduate education, and gives some constructive suggestions for them.
\end{abstract}

\section{Introduction}

As one of China's education output provinces, Jilin Province transported a large number of talents for many industries, and these talents provided supports for the overall country's economic development and social progress. With the popularization of higher education in China, the main subjects of social interests put forward higher requests to the graduate education. This trend has forced the government, universities and education researchers to focus on the construction and improvement of the graduate education system [1]. Though their cooperation, they hope to further coordinate the balance between the quantity and quality of graduate education, to adjust the structure and benefits of graduate education in Jilin Province.

Graduate education in Jilin province education can be traced back to the founding of new China. In 1949, the Northeast Administration College (now called Jilin University) organized a graduate class. Changchun Institute of Optics and Fine Mechanics (now named Changchun University of Science and Technology) were formally approved by the national government, to become a authority institute for training graduate students in 1958 [2]. In 1996, Jilin University was admitted as the first batch of national key universities which can run the graduate school [3]. After 4 years, Northeast Normal University was approved the pilot graduate school, formally joined the ranks of 53 national universities which has graduate school [4]. At present, there are 22 postgraduate training units in Jilin Province, including Yanbian University, Northeast Dianli University, Beihua University, Jilin Agricultural University, etc. As of the end of 2014, they had educated more than 230 thousand masters and doctoral students involving philosophy, economics, education, literature and other 7 categories. Postgraduate education showed a stable development trend, the specific data are shown in the Table 1.

Table 1 Development data of graduate education in Jilin province from 2000 to 2014 [5]

\begin{tabular}{|l|l|l|l|l|l|l|l|l|l|l|l|l|l|l|l|}
\hline Year & 2000 & 2001 & 2002 & 2003 & 2004 & 2005 & 2006 & 2007 & 2008 & 2009 & 2010 & 2011 & 2012 & 2013 & 2014 \\
\hline $\begin{array}{l}\text { Graduates } \\
\text { (person) }\end{array}$ & 1977 & 2064 & 2795 & 4227 & 5888 & 6798 & 8946 & 14030 & 12468 & 12739 & 12340 & 14312 & 15739 & 17489 & 17003 \\
\hline $\begin{array}{l}\text { New student } \\
\text { enrollment } \\
\text { person) }\end{array}$ & 4465 & 5828 & 6919 & 9590 & 11983 & 13158 & 13931 & 14452 & 15054 & 16845 & 17624 & 17988 & 18665 & 18942 & 19660 \\
\hline $\begin{array}{l}\text { Number of } \\
\text { postgraduate } \\
\text { enrollment } \\
\text { person) }\end{array}$
\end{tabular}


As the Table 1 shown, the graduate education in Jilin province are showing a steady development status, whether it is the establishment of training institutions or the annual enrollment scale. Due to the rapid growth in the number of colleges and universities, the proportion of graduate students training units in the province's colleges and universities began to decline from 2010, but on the whole, the selection and setting state of graduate students training institution are more rational in Jilin Province.

\section{Current Situation of Graduate Education in Jilin Province}

In the phase of popularization of higher education, the higher education in Jilin province faces some problems, such as pay more attention to the quantity of education but despise the quality of education, so its quality and efficiency is widely questioned. Not only the overall quality of undergraduate students is difficult to meet the requirements of talent market, but also graduate students are suffering the embarrassment of difficult employment. Facing this situation of higher education, Jilin provincial government, universities, enterprises and institutions work together to try to build a more reasonable and effective system for postgraduate education, to ensure the overall quality of graduate education. In the aspect of government, Education Department of Jilin Province focuses on national policy guidance, in the context of national education policies, to make the graduate education program which can conform to the characteristics of regional development. At present, Jilin province has developed and perfected the postgraduate education innovation project for coming 7 years. This project clearly shows that the postgraduate education should achieve a series of objective and construct some main platforms by 2020 .

In the aspect of universities, graduate education in Jilin province mainly relys on some key universities. In order to meet the talents' requirements from the government and society, these universities are actively seeking more effective cultivating models of graduate education. Now in Jilin Province 22 universities which have the cultivate authorize of graduate education are trying to jointly build the innovation training base with government and enterprises, and striving to complete the training of high-level talents who are the urgent need for petroleum chemical industry, electronic information industry, biological and medicine industry, new energy and other industries in Jilin Province. In the aspect of enterprises in Jilin Province, the various organizations gradually realized the important role of the enterprise in the area of talent's training, and tried to cooperate with universities from different angles and levels in the graduate education. As early as 2006, China's FAW Group Corporation signed a strategic cooperation agreement with Jilin University, jointly developed the talents for automotive industry. Eurasian Group also has established contact with the Northeast Normal University, to provide internship opportunities for graduate students. Yatai Group had cooperation with Changchun University of Science and Technology in term of jointly training talents. Postgraduate education in Jilin province has made some achievements in the development for these years, mainly in the aspects of quantity, quality and structure. In terms of the education quantity, according to the data provided by the Jilin Statistical Yearbook from 1989 to 2014, in Jilin province the enrollment quantity and output quantity of graduate student showed a state of oscillation, but its basic trend of development maintained positive, the grown trend as shown in Fig. 1.

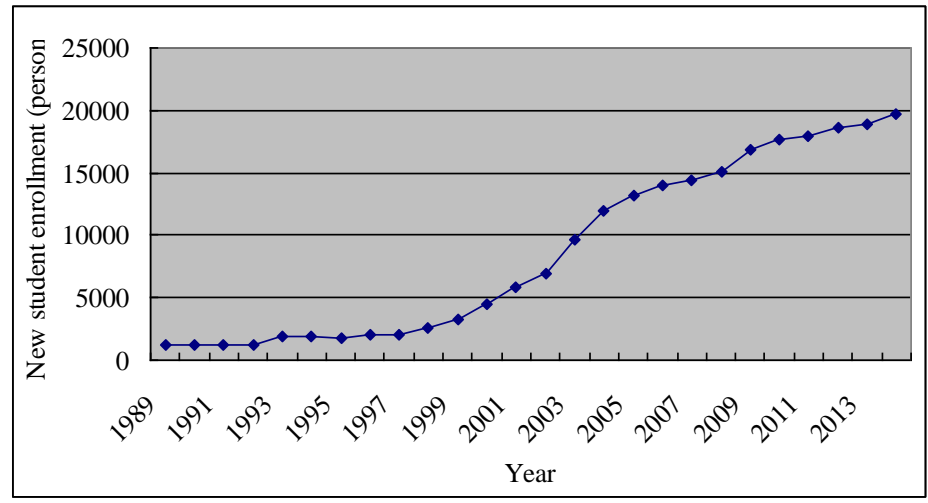


Figure 1. Growth trend of postgraduate enrollment in Jilin province from 1989 to 2014 [6]

By Fig. 1 shows, the enrollment number of graduate students in Jilin Province appeared to reduce trend in individual years during 30 years, but it remained steady growth since 2000, that indicating that graduate education in Jilin Province had a relatively stable development in terms of quantity. In terms of quality, graduate education in Jilin province has been to PBL teaching mode, and the learning form of students is mainly involved in the practice of teachers and research projects, in some extent, which ensures the professional quality of graduate students. At the same time, some universities headed by Jilin University have developed the quality evaluation index system for graduate education and some evaluation indexes for doctoral students up to more than 100. These indexes have provided a guarantee for the graduate's overall quality. In the aspects of education structure, by the end of 2014, the specialty provision of 22 universities which can train graduate students in Jilin Province covered all categories of social sciences and natural sciences, and gradually extended to the emerging industries and innovative areas.

\section{Analysis on the Problems and Its Reasons of Graduate Education in Jilin Province}

Compared to other regions of China, graduate education in Jilin Province started earlier and had made impressive achievements in the exploration and development of higher education. But there are still some problems that can not be avoided, such as overall structural imbalance in the system of graduate education, lack of effective monitoring in the management, inadequate implementation of various policies and programs and so on.

Imbalance Development between Academic Education and Professional Education. Graduate education system is divided into two categories, namely "academic degree" and "professional degree" [7]. In 1996, Jilin University became the first batch of pilot units in the field of graduate education for professional degree in China. However, after more than ten years of development, the development of professional degree graduate education is not ideal. Since the beginning of 2009, higher education departments of government in China had begun to adjust the enrollment proportion between academic degree graduate students and professional degree graduate students. The scale of professional degree graduate students has been a certain degree of improvement, but compared with academic degree, their social awareness is relatively lower. At the same time, the institutions or universities show some "unfair" phenomenon in the process of two types of graduate education development. More educational resources allocated to the academic degree in the field of graduate student education, and less allocated to professional degree education [8]. The main reason for the above problems is less attention from the social public, enterprises, institutions and even higher institutions themselves in Jilin province, they believe that the quality of professional degree in the graduate education for its shorter education period.

Unfavorable Quality of Graduate Education. For more than 60 years, under their joint efforts, many scientific research institutions and universities in Jilin Province have provided a lot of high-level talents for society, but with the continuous scale expansion of higher education, the quality of education has encountered unprecedented challenges. In recent years, the education quality of graduate students in Jilin Province has been questioned by mass, due to the professional and moral quality of graduate students, who had already graduated and been employed, can not meet the demands of employers.

The reason of that situation is mainly lack of effective supervision of the education quality in the postgraduate education system, which led to the phenomenon of "admission is difficult, but graduation is easy" in the graduate education. The screening efforts in the part of enrollment should be able to guarantee the basic quality of the graduate students, but how to enhance their professional ability after they are smoothly enrolled becomes the source of problems. In Jilin Province graduate education shows different patterns in different majors. The graduate education model of liberal arts is relatively free that their graduate students can voluntarily participate in their tutor's scientific research projects or 
can choose to "do nothing". This kind of education mode with the students who are lack of learning initiative finally led to the lower level quality of graduate education in graduate education. In order to reverse this situation, many institutions and universities have designed the evaluation standard of graduate education quality now, but the dimension or the weight of these standards are not very mature and need to improve.

Inadequate Implementations of Various Policies and Programs. In order to ensure the smooth development of graduate education, the government of Jilin Province has introduced a lot of guidance documents, while the research institutions and universities also have designed the model and program for their graduate education. But in fact, a lot of programs just stay in the stage of planning, with more formal, and their practice is not powerful. For example, many universities in Jilin Province have tried to use the scientific research projects to exercise and improve the scientific research ability of their graduate students, but most of the students only participated in the proposal stage and knot phase of project, which resulted in the low quality of scientific research project and a serious waste of resources. In addition, in recent years, some universities have actively tried to attract more high-level tutors by inviting some external experts, but graduate students may only see that tutor when issued letters of appointment.

\section{Improvement of Graduate Education System in Jilin Province}

Reverse the Wrong Understanding. The main reason of the above problems in the process of graduate education in Jilin province is the misunderstanding of educational idea and cognition [9]. Therefore, the key to improve the current situation is to reverse the wrong understanding by both internal and external efforts. The government need to increase the guidance of graduate education, makes the public and the universities to realize the true role of graduate education, so that the public can make rational choice about graduate education and the universities can take scientific planning on it. The institutions and universities which can educate the graduate students should clear the focus of education, gives targeted resources for different categories, different majors and different levels of graduate students.

Establish a Perfect Quality Evaluation Index System. At present, there have been a lot of researches about quality evaluation index system for graduate education, but the involved areas and universities of these researches are mostly located in South of China, for Jilin Province these results have only reference value, can not use them directly. Therefore, the top priority of the Jilin Province should analyze and demonstrate the formed index system, take its essence and discard its dregs, to sort out those with the applicability and practicability of quality evaluation index systems for graduate education, to make the stage evaluation to the process of graduate education, to ensure that the target of graduate education reached.

Build a Win-win Strategic Alliance. Talents' training has never been a thing of the University that needs the joint actions of the interests of all communities. The education of high-level talents should be more greatly helped by social forces, especially enterprises and institutions [10]. But in recent years, the actual effect of the school-enterprise cooperation is not very good. Often the news is very lively but the actual operation can not follow. The main reason for the difficult operation of the school-enterprise cooperation is not a win-win situation. In the process of school-enterprise cooperation for training talents, enterprises will take greater risks, such as data leakage, brain drain etc.. In order to reduce these risks, enterprises choose "the surface cooperation" that naturally will not receive ideal effect. So, in the process of school-enterprise cooperation to build a talent training base for graduate education we may wish to "reality", so that both sides have enough "benefit" as a driving element, to build a win-win strategic alliance between universities and enterprises.

\section{Conclusion}

This paper analyzes the current situation of graduate education in Jilin Province, finds out the existing problems and their reasons, and puts forward the countermeasures to improve the graduate education 
system of Jilin province. As the research data is the secondary data, so this study has some limitations. In the Future, the research can obtain first-hand data through questionnaire survey directly, and use empirical method to study the graduate education of Jilin province, such as the education satisfaction of graduate students in Jilin province etc..

\section{Acknowledgements}

This work was financially supported by Educational Science Foundation of Jilin Provincial Education Department (Project Title: Research on exploration and practice about innovation mode of graduate education in university alliance--a case study of Jilin Province, No. GH14409).

\section{References}

[1] W.H. Zhou, Z.J. Wang, J.Q. Liu, M.L. Li, X.B. Wu, Y.Q. Zhou and Q.H. Zhao: Academic Degrees \& Graduate Education, Vol.29 (2012) No.12, p.34-40.

[2] Information on http://yjs.ciomp.ac.cn/

[3] Information on http://yjsy.jlu.edu.cn/yjsynew/yjsy_gk/

[4] Information on http://www.nenu.edu.cn/253/list.htm

[5] Jilin Statistical Bureau and Survey Office of the National Bureau of Statistics in Jilin: Jilin Statistical Yearbook, (China Statistics Press, China, From 2001 to 2015).

[6] Jilin Statistical Bureau and Survey Office of the National Bureau of Statistics in Jilin: Jilin Statistical Yearbook, (China Statistics Press, China, From 1990 to 2015).

[7] M. Wan: Study on the Reform of Chinese Graduate Education System (Ph.D., University of Science and Technology of China, China), p.107.

[8] Y. Hong, B.L. Zhong, Y.S. Zhao and X.Q. Zhang: China Higher Education Research, Vol.28 (2012) No.7, p.41-46.

[9] X.L. Bai: Education and Vocation, Vol.48 (2015) No.6, p.178-179.

[10] Y.L. Guo: Academic Degrees \& Graduate Education, Vol.31 (2014) No.6, p.49-54. 